\title{
Study of Ear-Face Index Among the Youth of Madhesis Community of Nepal
}

\author{
Sah $\mathrm{SK}^{1^{*}}$, Pandey $\mathbf{N}^{2}$, Singh $\mathrm{AC}^{3}$ \\ ${ }^{1}$ Assistant Professor, Dept. of Anatomy, Nobel Medical College and Teaching Hospital, Biratnagar, Nepal. \\ ${ }^{1} \mathrm{PhD}$ Scholar, Singhania University, Pacheri Bari, Jhunjhunu, Rajasthan, India \\ ${ }^{2}$ Professor, NC Medical College, Panipatt, India. \\ ${ }^{3}$ HOD \& Professor, Dept. of Anatomy, Nobel Medical College and Teaching Hospital, Biratnagar, Nepal. \\ DOI: 10.29322/IJSRP.10.11.2020.p10747 \\ http://dx.doi.org/10.29322/IJSRP.10.11.2020.p10747
}

\begin{abstract}
INTRODUCTION: Ear is an important complex of the facial complex, which gives an impression of the bearer's age and sex. From aesthetic point of view the shape, size and spatial location of the ears are very important. Any abnormality is an indication of anomaly in the subject. The biometrics of ear is a very interesting issue as during crime scene investigation, ear marks and measurements are often used for identification in the absence of valid fingerprints. Ear biometrics can positively identify an individual using comparative analysis of the human ear and its morphology.
\end{abstract}

MATERIALS AND METHODS: This study was carried out among residents of Ramnagar Gaupalika-7, Sarlahi,Nepal, one of the core region of Madhesh Nepal dated Jan2020 to March2020 .The cohort consists of independent adults of age group 17-35 and consenting adults from the metropolis. Ethical approval was sought and obtained from the supervising ethical committee of the Nobel Medical College Teaching Hospital, Biratnagar, Nepal. Consent for the recruitment of the subjects were taken from the subjects by taking written consent. Subjects were randomly selected and those that had scars on the ears other than the usual ear piercing for rings and those with observable defect or growths were excluded from the study. No interventions or investigations were done. Only digital photography were taken. This caused no harm to the subjects. The photographs were used for research purpose only. Sample size: 50 male and 50 female.

RESULTS: Mean facial height of 193.92 (19.66) mm. for males was significantly longer than the facial height of women $169.68(17.21) \mathrm{mm}$. The ear face indices were 33.86 (3.18) \% and $33.08(3.05) \%$ in males, right and left respectively and 36.76 (3.55)\% and 35.40 (3.44)\% in females. The mean ear heights were 65.25(5.88) $\mathrm{mm}$ for right ear and $63.80(5.95) \mathrm{mm}$ for left ear for the male individuals. Whereas for female the mean ear height for right side was 62.06 (3.79) $\mathrm{mm}$ and 59.69 (3.86) $\mathrm{mm}$ for left ear. There were significance differeneces between both the ear height in both the genders male and female.

DISCUSSION: Significant variations exist between the male and the female sexes in height of ear as well as the facial height and ear-face index. Several studies have indicated that male facial height was higher than female's. ${ }^{13}$ This study has also confirmed that the length of face in case of male individual is significantly larger than that of the female. The ear- face index also concludes that the larger index in case of female as compare to the male might be because of the aesthetic purpose.
CONCLUSION: Significant variations do exist among ethnic groups and, and sexual dimorphism also do exist. The data obtained in our study may be useful as a reference for facial analyses that will be further useful in anthropological research, forensics, genetic research, medical clinical practice (reconstructive surgery) and in cosmetology. This study will serve as a basis of comparison for future studies in other ethnic group of Nepali population.

Index Terms- Anatomy, Anthropometry, External Ear, E-F Index, Gender Variation

\section{INTRODUCTION}

$\mathrm{E}$ ar is an important complex of the facial complex, which gives an impression of the bearer's age and sex. From aesthetic point of view the shape, size and spatial location of the ears are very important. Any abnormality is an indication of anomaly in the subject. ${ }^{1}$ The shape and size of ear is influenced by the age, sex and ethnic origin. Abnormalities of the ear such as missing external ear, prominent ears, lobule ptosis and microtia may result from trauma, surgical resection, tumours, or congenital deformities. For the psychological stability of the subjects also the surgical correction of the anomalies are required. ${ }^{2}$ The biometrics of ear is a very interesting issue as during crime scene investigation, ear marks and measurements are often used for identification in the absence of valid fingerprints. Ear biometrics can positively identify an individual using comparative analysis of the human ear and its morphology. The dimensions of the pinna have been found to vary among different ethnic groups. ${ }^{3}$ The external ear consists of the auricle or pinna, and the external acoustic meatus. The auricle projects to a variable and individual degree from the side of the head and collects sound waves, which it conducts along the external acoustic meatus to the eardrum, the tympanic membrane. The external ear is composed of three primary components; the helix-antihelical complex, the conchal complex, and the lobe. ${ }^{4}$ The visible part is called the auricle, also known as the pinna, especially in other animals. It is composed of a thin plate of yellow elastic cartilage, covered with integument, and connected to the surrounding parts by ligaments and muscles; and to the commencement of the ear canal by fibrous tissue. Many mammals can move the pinna (with the auricularis muscles) in order to focus their hearing in a certain direction in much the 
same way that they can turn their eyes. Most humans do not have this ability. One consequence of the configuration of the outer ear is selectively to boost the sound pressure 30 - to 100 -fold for frequencies around $3 \mathrm{kHz}$. This amplification makes humans most sensitive to frequencies in this range - and also explains why they are particularly prone to acoustical injury and hearing loss near this frequency. Most human speech sounds are also distributed in the bandwidth around $3 \mathrm{kHz} .^{5}$

The face is the anterior part of an human's head that bear three of the head's sense organs, the eyes, nose, and mouth, and through which animals express many of their emotions. The face is crucial for human identity and damage such as scarring or developmental deformities affects the psyche adversely. The face is the feature which best distinguishes a person. Specialized regions of the human brain such as the fusiform face area (FFA), enable facial recognition; when these are damaged, it may be impossible to recognize faces even of intimate family members. The pattern of specific organs, such as the eyes, or of parts of them, is used in biometric identification to uniquely identify individuals. The shape of the face is influenced by the bone-structure of the skull and each face is unique through the anatomical variation present in the bones of the viscerocranium (and neurocranium. The bones involved in shaping the face are mainly the maxilla, mandible, nasal bone and zygomatic bone. Also important are various soft tissues, such as fat, hair and skin. ${ }^{6}$ Facial shape is an important determinant of beauty, particularly facial symmetry.

Craniofacial anthropometry, as an important part of anthropology and medicine, is used for the determination of the morphological characteristics of the head and face. Face shape depends on many factors, such as gender, race and ethnicity, climate, socio-economic, nutritional, and genetic factors. The determination of facial parameters is of great importance for the evaluation of facial trauma, congenitaland traumatic deformities and easier identification of certain congenital malformations. ${ }^{7}$ The collected data can be used in anthropology and forensic medicine for identification of racial and sexual differences as well as in reconstructive surgery for facial reconstruction.

Facial height is the distance between trichion to gnasion.Trichion (tr) is the point on the hairline in the midline of the forehead, gnathion (gn) is the lowest median landmark on the lower border of the mandible.

Anthropologists use it for people of Indian ancestry residing in Terai of Nepal and comprising various cultural groups such as Hindu caste groups, muslims , merchants and indigenous people of the Terai. ${ }^{8}$

Madheshi people comprise caste groups like Brahmin, Teli, Suri, Yadav, Gupta, Kayastha, Bhumihar and Dalit as well as ethnic groups such as Maithils , Bhojpuri , Awadhi and Bajjika speaking people. ${ }^{9}$ Indian immigrants settled foremost in present-day eastern Nepal Terai since the late 18th century, when the rulers of Nepal encouraged deforestation and agricultural development of this region. ${ }^{10}$

\section{MATERIALS AND METHODS:}

This study was carried out among residents of Ramnagar Gaupalika-7, Sarlahi,Nepal, one of the core region of Madhesh Nepal dated Jan2020 to March 2020.The cohort consists of independent adults of age group 17-35 and consenting adults from the metropolis. Ethical approval was sought and obtained from the supervising ethical committee of the Nobel Medical College Teaching Hospital, Biratnagar, Nepal. Consent for the recruitment of the subjects were taken from the subjects by taking written consent. Subjects were randomly selected and those that had scars on the ears other than the usual ear piercing for rings and those with observable defect or growths were excluded from the study. No interventions or investigations were done. Only digital photography were taken. This caused no harm to the subjects. The photographs were used for research purpose only.

Sample size: 50 male and 50 female.

\section{PROTOCOL OF THE PROCEDURE:}

- For the purpose of this study, unique digital signal processing technology, the megapixel camera was used to enable high-resolution system.

- The subjects were made to sit comfortably on a chair in such a way that the subject looking straight forward keeping the face in Frankfurt's line, i.e., the inferior border of orbit and center of external acoustic meatus lies in the same horizontal line with a white ruler placed behind the pinna exactly parallel to the auricle.

- Lateral surface of the auricle was photographed in such a way that mid-vertical grid line of the camera aligned to pass through the mid-saggital plane of the face while the mid-horizontal pass through the Frankfurt's plane .

- Digital images were transferred to a computer and the images were analyzed with Adobe Photoshop software (version 7.0, Adobe systems, San Jose, California). First of all, various soft tissues landmarks were tagged on the subject's ear photograph and then different parameters were measured by Image J 1.48 software Image J (v 1.48 Jawa1.6.0_20 64bits).

The following anthropometric parameters were measured by indirect method and variation according to age and sex:

1. Ear height: supra-aurale to sub-aurale.

2. Facial height: trichion to gnasion.

3. Ear-face index = ear height/ face height $\times 100$.

\section{Statistical Analysis:}

The results were calculated as mean \pm standard deviation. The Pearson correlation will be used to institute the association between age, sex, and external ear anthropometry. The data were analyzed using BM SPSS Statistics for Windows, Version 20.0.Armonk, NY;IBM Corp., and $\mathrm{p} \leq 0.05$ considered as level of significance.

\section{RESULTS:}

In present study, 100 individuals were selected with age of 18 to 35years were selected and consisting of 50 males and 50 females individual. According to the obtained data the following parameters were recorded.

\section{Facial Parameters}


The facial height for male ranged from $148 \mathrm{~mm}$ to $237 \mathrm{~mm}$. The mean was 193.92 (19.66) $\mathrm{mm}$ for male individual. The facial height for female ranged from $138 \mathrm{~mm}$ to $193 \mathrm{~mm}$. The mean was 169.68 (17.21)mm for female individuals.

Mean facial height of 193.92 (19.66) mm. for males was significantly longer than the facial height of women 169.68 (17.21) $\mathrm{mm}$. The ear face indices were 33.86 (3.18) \% and $33.08(3.05) \%$ in males, right and left respectively and 36.76 $(3.55) \%$ and $35.40(3.44) \%$ in females.

\section{Ear Parameters}

Ear Height: The mean ear heights were 65.25(5.88) $\mathrm{mm}$ for right ear and $63.80(5.95) \mathrm{mm}$ for left ear for the male individuals. Whereas for female the mean ear height for right side was 62.06 (3.79) $\mathrm{mm}$ and 59.69 (3.86) $\mathrm{mm}$ for left ear. There were significance differeneces between both the ear height in both the genders male and female. The mean height of male ear were greater than that of the female individuals.

Table:1 -Descriptive Statistics for measurements of male for right ear Sample size

\begin{tabular}{llllll} 
& $(\mathbf{N})$ & Minimum & Maximum & Mean & Std. Deviation \\
\hline R. EAR HEIGHT & 50 & 50 & 76 & 65.25 & 5.883 \\
\hline FACIAL HEIGHT & 50 & 148 & 237 & 193.92 & 19.664 \\
\hline E-F INDEX & 50 & 28 & 42 & 33.86 & 3.182 \\
\hline Valid N (listwise) & 50 & & & & \\
\hline
\end{tabular}

Table: 2- Descriptive Statistics for measurements of Male for left ear Sample size

\begin{tabular}{llllll} 
& $(\mathrm{N})$ & Minimum & Maximum & Mean & Std. Deviation \\
\hline L.EAR HEIGHT & $\mathbf{5 0}$ & 48 & 75 & 63.80 & $\mathbf{5 . 9 5 5}$ \\
\hline FACIAL HEIGHT & 50 & 148 & 237 & 193.92 & 19.664 \\
\hline E-F INDEX & 50 & 27 & 41 & 33.08 & 3.050 \\
\hline Valid N (listwise) & 50 & & & & \\
\hline
\end{tabular}

Table: 3-Descriptive Statistics for measurements of Female on right ear

\begin{tabular}{llll|l|l|l} 
& $\begin{array}{l}\text { Sample size } \\
(\mathbf{N})\end{array}$ & Minimum & Maximum & Mean & Std. Deviation \\
\hline R. EAR HEIGHT & 50 & 56 & 70 & 62.06 & 3.795 \\
\hline FACIAL HEIGHT 50 & 138 & 193 & 169.68 & 17.217 \\
\hline E-F INDEX & 50 & 32 & 46 & 36.76 & 3.555 \\
\hline Valid N (listwise) & 50 & & & & \\
\hline
\end{tabular}

Table: 4-Descriptive Statistics for measurements of female on left ear Sample size

\begin{tabular}{llllll} 
& $(\mathrm{N})$ & Minimum & Maximum & Mean & Std. Deviation \\
\hline L.EAR HEIGHT & 50 & 52 & 68 & 59.69 & 3.865 \\
\hline FACIAL HEIGHT & 50 & 138 & 193 & 169.68 & 17.217 \\
\hline E-F INDEX & 50 & 31 & 44 & 35.40 & 3.440 \\
\hline Valid N (listwise) & 50 & & & & \\
\hline
\end{tabular}

\section{DISCUSSION}

The mean ear height for both right and left ears in this study was similar to the study done by Sullivan et al, where the mean height of ear was $63 \mathrm{~mm} .{ }^{11}$ There was statistically significant asymmetry between the height of ear on right and left side which is similar to the findings of Sforza et al. ${ }^{12}$ The left ear height was smaller than that of the right side throughout the cohort study. The possible reason behind this asymmetry may be the genetic and the ethnic factor.
Significant variations exist between the male and the female sexes in height of ear as well as the facial height and ear-face index. Several studies have indicated that male facial height was higher than female's. ${ }^{13}$ This study has also confirmed that the length of face in case of male individual is significantly larger than that of the female. The ear-face index also concludes that the larger index in case of female as compare to the male might be because of the aesthetic purpose.

The mean facial height observed in our study $(193.92 \mathrm{~mm}$ \pm 19.66 ) for male was higher than the value obtained in a survey conducted among residents of Benin city Nigeria (183.0 \pm 21.6 $\mathrm{mm})$, for female $(169.68 \pm 17.21 \mathrm{~mm})$ lower than $(176.9 \pm 19.5)$, 
where all the age groups were considered in the study. The mean E-F index for male and female was higher than that of their study. ${ }^{14}$ The data obtained in the present study may be useful in anthropological research, forensics, genetic research, as well as in medical clinical practice (reconstructive surgery). As particularly the youth of Madhesis community were considered.

There were distinct variations in ear proportions among the ethnic groups studied is unlikely to be noticeable at conversational distance. However, it demonstrates recognizable ethnic characteristics with both anthropological and forensic implications. The variation is likely to be genetic. Such variations have been described in multi-ethnic populations and their characterizations have been applied in reconstruction and ejuvenation procedures. So among the Madhesis community on the basis of morphology of face and ear it can be easily identified that the individual belongs to the community on the basis of above data.

\section{CONCLUSION:}

From our present study, we conclude that the mean total height of ear and total height of face in case of male was higher than that of the female in Madhesis community. The mean E-F index is however in male is lower than that of the female individuals. Significant variations do exist among ethnic groups and, and sexual dimorphism also do exist. The data obtained in our study may be useful as a reference for facial analyses that will be further useful in anthropological research, forensics, genetic research, medical clinical practice (reconstructive surgery) and in cosmetology. This study will serve as a basis of comparison for future studies in other ethnic group of Nepali population.

\section{ACKNOWLEDGEMENT:}

First of all I would like to thank the rural ward director of Ramnagar-7 Gaupalika, Sarlahi, Nepal for giving me the opportunity to carry out the study. And special thanks go to my brother Radhe Shyam Sah and the respondents for co-operating in data collection. At last I would like to thank my HOD and Nobel Medical College for allowing me to go for data collection.

\section{REFERENCES}

[1] Ruma P, Singh P. Anthropometry of the normal human auricle: A study of Adult Indian Men. Journal of Aesth Plast Surg 2007;31:372-79.

[2] Coward TJ, Watson RM, Scott BJJ. Laser scanning for the identification of repeatable landmarks of the ears and face. Br J Plastic Surg;1997;50:308-14.

[3] Kumar P, Singla A. Ear biometric: sex, bilateral and ethnic differences among brahmin and yadav communities of Bundelkhand region using PCA technique. Int J Scientific \& Eng Res. 2013;4:799-805.
[4] Stark L, Malone M, Starr H (2008). Inherited Human Traits: A Quick Reference. University of Utah, from: http://learn.genetics.utah.edu.Sykes, B. (1993): Introduction to medical genetics. In Connective Tissue and Its Heritable Disorders Wiley-Liss: New York; 7-50.

[5] Purves, Dale, George J. Augustine, David Fitzpatrick, William C. Hall, Anthony-Samuel LaMantia, James O. McNamara, and Leonard E. White (2008). "Chapter 13". Neuroscience. 4th ed. Sinauer Associates. p. 317. ISBN: 978-0-87893-697-7.

[6] Moore, Keith L.; Dalley, Arthur F.; Agur, Anne M. R. (2010). Moore's clinical anatomy. United States of America: Lippincott Williams \& Wilkins. pp. 843-980. ISBN 978-1-60547-652-0.

[7] Oladipo, G.S., Didia, B.C., Okoh, P.D., and J.S. Hart (2008a). Sexual dimorphism in facial dimensions of adult Ijaw. J. Expt. and Clin. Anat. 7 (2), $10-14$.

[8] Whelpton, J. (1997). "Political Identity in Nepal: State, Nation and Community". In Gellner, D.N.; Pfaff-Czarnecka, J.; Whelpton, J. (eds.). Nationalism and ethnicity in a Hindu kingdom: The politics of culture in contemporary Nepal. London, New York: Routledge. pp. 39-78.

[9] Hachhethu, K. (2007). "Madheshi nationalism and restructuring the Nepali state". International Seminar on Constitutionalism and Diversity in Nepal. Tribhuvan University, Kathmandu: Centre for Nepal and Asian Studies. pp. $1-12$

[10] Dahal, D.R. (1983). "Economic development through indigenous means: A case of Indian migration in the Nepal Terai" (PDF). Contribution to Nepalese Studies. 11 (1): 1-20.

[11] Sullivan PK, Brucker MJ, Patel J. A morphometric study of the external ear: age and sex related differences. Plast Reconstr Surg.2003; 112(2): 647- 652.

[12] Sforza C, Grandi G, Binelli M, Tommasi DG, Rosati R, Ferrario VF. Age and sex related changes in the normal human ear. Forensic Sci Int. 2009; 187(13): 1-7.

[13] Farkas LG, Posnick JC, Hreczko TM. Growth patterns of the face: A morphometric study.Cleft Palate Craniofac J. 1992; 29: 308-315.

[14] Oluderan $\mathrm{OO}$ et al, A morphometric study of the external ears at Benin City. Nigerian Journal of Plastic Surgery 2012

\section{AUTHORS}

First Author - Sah SK, Assistant Professor, Dept. of Anatomy, Nobel Medical College and Teaching Hospital, Biratnagar, Nepal. PhD Scholar, Singhania University, Pacheri Bari, Jhunjhunu, Rajasthan, India

Second Author - Pandey N, Professor, NC Medical College, Panipatt, India.

Third Author - Singh AC, HOD \& Professor, Dept. of Anatomy, Nobel Medical College and Teaching Hospital, Biratnagar, Nepal.

Correspondence Author - Surendra Kumar Sah PhD Scholar(Anatomy), Singhania University, Pacheri Bari, Jhunjhunu, Rajasthan, India. , Assistant Professor, Dept. of Anatomy, Nobel Medical College and Teaching Hospitals, Nepal, Tel:+9779842457021 Email: suren.anat2010@gmail.com 